\title{
Interorganizational macrocultures: A multilevel critique
}

Link to publication record in Manchester Research Explorer

\section{Citation for published version (APA):}

Healey, M., Hodgkinson, G. P., Ashkanasy, N. M. (Ed.), Wilderom, C. P. M. (Ed.), \& Peterson, M. F. (Ed.) (2011). Interorganizational macrocultures: A multilevel critique. In The Handbook of Organizational Culture and Climate (2nd ed., pp. 291-316). Sage Publications Ltd. http://www.uk.sagepub.com/books/Book233478

\section{Published in:}

The Handbook of Organizational Culture and Climate

\section{Citing this paper}

Please note that where the full-text provided on Manchester Research Explorer is the Author Accepted Manuscript or Proof version this may differ from the final Published version. If citing, it is advised that you check and use the publisher's definitive version.

\section{General rights}

Copyright and moral rights for the publications made accessible in the Research Explorer are retained by the authors and/or other copyright owners and it is a condition of accessing publications that users recognise and abide by the legal requirements associated with these rights.

\section{Takedown policy}

If you believe that this document breaches copyright please refer to the University of Manchester's Takedown Procedures [http://man.ac.uk/04Y6Bo] or contact uml.scholarlycommunications@manchester.ac.uk providing relevant details, so we can investigate your claim.

\section{OPEN ACCESS}


снаттев 16

\title{
Interorganizational Macrocultures
}

\author{
A Multilevel Critique
}

Gerard P. Hodgkinson and Mark P. Healey

\begin{abstract}
Management theorists generally define organizational culture as relatively idiosyncratic, organization-related beliefs that are shared among individuals within an organization or part of an organization ... We describe this as the prevailing focus the field places on organizational microcultures and distinguish it from what we term interorganizational macrocultures, by which we mean the relatively idiosyncratic, organization-related beliefs that are shared among top managers across organizations.
\end{abstract}

(Abrahamson \& Fombrun, 1994, p. 730)

$\mathrm{I}$ $\mathrm{n}$ the immediate aftermath of the tumultuous global financial crisis of recent years, one thing is clear-namely, that the overwhelming consensus within and between the banks and related financial institutions regarding the practices associated with the unchecked growth in the housing and stock markets contributed to a collective blind spot that desensitized organizations and entire industries to the attendant risks in the event that the bubble should burst. This prevailing mind-set eschewed concerns over the potentially catastrophic knock-on effects of risky mortgage lending and other questionable practices. Yet the most surprising thing is not that decision makers made errors of judgment,

but that the faulty logic underpinning those judgments was endorsed so universally and unquestionably from within. How could this situation have arisen? One concept that sheds light on these recent events is the notion of interorganizational macrocultures. Abrahamson and Fombrun (1994, p. 730) advanced this concept to capture the fact that top managers across organizations share "relatively idiosyncratic, organizationrelated beliefs." These shared beliefs, which are fundamental to the boundary definitions adopted to characterize particular classes of organizations and manage the attendant reputational dynamics within and across those groupings, are both generated by and mirror 
the value-added networks that configure organizations into such collectives. According to Abrahamson and Fombrun (1994), the tendency of macrocultures to homogenize over time accounts for the all too frequent failure of entire industries to adapt to radically new competitors and technological innovations, clinging instead to outmoded practices and competitive positioning strategies. As shown in Figure 16.1, homogeneous macrocultures restrict the inventiveness of, and diffusion of innovations among, member organizations, thereby driving them toward collective inertia and increasing the similarity of their strategic profiles.

This chapter provides a selective review of the current state of knowledge concerning

PRESENT

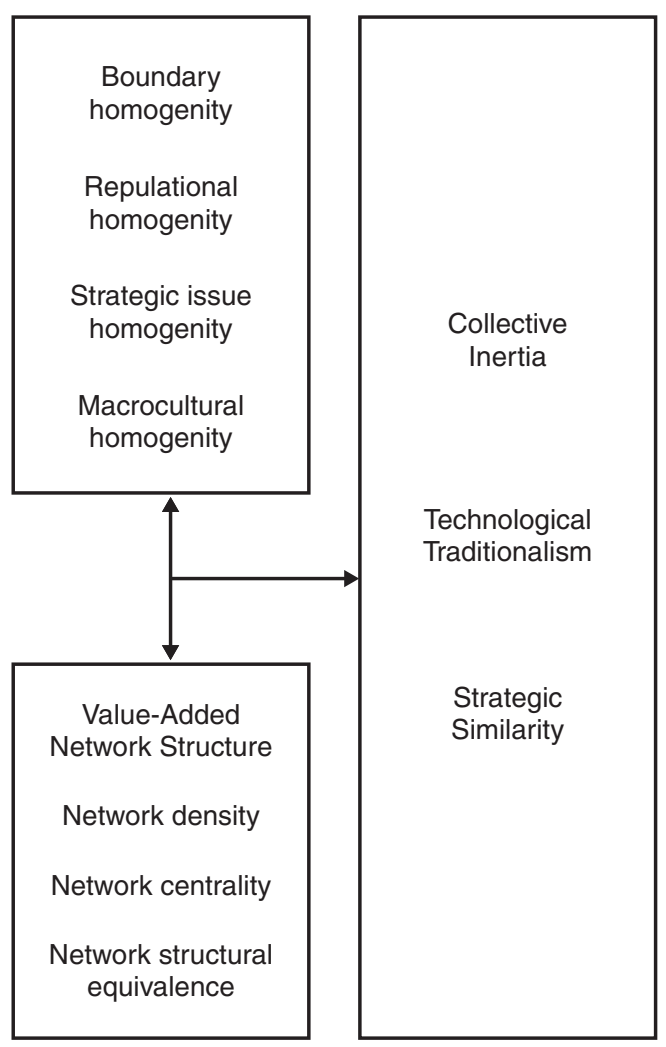

Figure 16.1 Macroculture: Present Determinants and Future Consequences

SOURCE: Abrahamson \& Fombrun, 1994, p. 738. the development and impact of macrocultures as a key shaper of the strategic behavior of organizations. Focusing purposively on the literature pertaining to the determinants and consequences of strategic actors' beliefs concerning the fundamental problem of competitor definition, our goal is to offer a constructive critique of the macroculture notion. We argue for a broader, multilevel conception of strategic adaptation, one that integrates the individual, group, organizational, and interorganizational levels in the analysis of the determinants and consequences of macrocultures. As will be demonstrated, when viewed from this perspective, researchers have barely begun to scratch the surface in attempting to gain an adequate understanding of how macrocultures exert their effects; nor, indeed, is it sufficiently clear how such cultures develop and change.

The chapter is organized in four main sections as follows. In the first section, we outline major theoretical developments and accompanying empirical findings advanced mainly by North American researchers, which highlight the importance of macrocultural processes for understanding the dynamics of interorganizational rivalry and the formation of discernable competitive structures in industries and markets. In the second section, we review a number of counter-theoretical arguments and alternative empirical evidence emanating largely from the United Kingdom and wider continental Europe, which suggest that this predominantly U.S. body of work has downplayed the significance of intra-organizational processes and individual differences in the development and mediation of macrocultures. However, we maintain that a number of theoretical and methodological shortcomings associated with the U.K.-European work need to be rectified in order to investigate more thoroughly the potential significance of organizational microprocesses and microcultural influences as determinants and mediators of interorganizational macrocultures. In order to 
address these issues, researchers need to adopt methods and research designs that will enable larger scale, multilevel inquiry and the simultaneous testing of hypotheses predicated upon the rival bodies of theory outlined. To date, very few studies have attempted to meet these challenges, but it is to this emerging body of work that we turn next in the third section. Finally, in the concluding section, we distil the major implications of our arguments for future theory development and research on organizational adaptation, beyond the confines of competitive dynamics per se.

\section{ORIGINS, DYNAMICS, AND CONSEQUENCES OF INTERORGANIZATIONAL MACROCULTURES}

\section{Basic Cognitive Processes Underpinning Competitor Definition}

As observed by Porac and Thomas (1990), to identify and respond to competitive pressures, strategists must first abstract from the myriad of diverse organizational forms and potentially salient interorganizational cues an image of whom their rivals are and on what dimensions they will compete. How actors develop such images of competitive space is a fundamental research question that has long occupied researchers situated at the nexus of organization theory and strategic management on both sides of the Atlantic. In the absence of basic agreement among a value chain's key stakeholders on the legitimacy of particular organizations to offer particular products and services, there can be no basis for the social construction of industries and markets (cf. Porac \& Rosa, 1996). Macrocultures are thus vital to the development of stable economies, and an analysis of the sociocognitive dynamics underpinning business rivalry is an essential complement to the perspective of industrial organization economics that has so long dominated the study of competition in the field of strategic management (e.g., Caves \& Porter, 1977; Oster, 1990; Porter, 1980).

As readily acknowledged by Abrahamson and Fombrun (1994), the conceptual foundations of the macrocultures notion were laid in a number of prior studies of how rival organizations come to be configured into discernibly meaningful collectives (e.g., Grinyer \& Spender, 1979; Gripsrud \& Gronhaug, 1985; Reger \& Huff, 1993; Walton, 1986). Particularly noteworthy in our view is the notion of industry recipes (Grinyer \& Spender, 1979; Spender, 1989), the idea that industrywide collectives of managers handle uncertainty by evolving shared beliefs about what works and what does not. Arguably, however, it is the theoretical (Levenhagen, Porac \& Thomas, 1993; Porac \& Thomas, 1990) and empirical (e.g. Porac \& Thomas, 1994; Porac, Thomas, \& Baden-Fuller, 1989; Porac, Thomas \& Emme, 1987) work of Porac and his colleagues, which has ultimately stimulated the most significant advances concerning the basic mechanisms underpinning the social construction and evolution of interorganizational belief systems that have occurred over the 16 years that have elapsed since the publication of the Abrahamson and Fombrun (1994) Academy of Management Review article (see also Porac \& Rosa, 1996; Porac, Thomas, Wilson, Paton, \& Kanfer, 1995).

The basic opening premise of Porac et al.'s work is that because strategic actors, like all decision makers, are fundamentally limited in terms of their capacity to process information, they attend to only a limited subset of competitors. Drawing on the insights of categorization theory from cognitive psychology (Rosch, Mervis, Gray, Johnson, \& Boyes-Braem, 1976), Porac and his colleagues (e.g., Porac et al., 1987, 1989; Porac \& Thomas, 1990, 1994; Porac \& Rosa, 1996) have argued that strategists' mental representations of competitors take the form of hierarchical taxonomies and that their attention is directed primarily toward intermediate, basic-level categories. 
It is at this basic level of abstraction that categories are optimal in terms of their information content because they possess the maximum proportion of unique attributes relative to the overlapping attributes of neighboring categories. Categorizing competitors in this way enables actors to simplify reality and hence take action within the constraints imposed by bounded rationality. Again drawing on the insights of categorization theory (e.g., Rosch, 1975), Porac and his colleagues maintain that competitors are grouped on a graded, as opposed to all-or-nothing, basis (see also Lant \& Baum, 1995; Lant \& Phelps, 1999; Peteraf \& Shanley, 1997; Reger \& Huff, 1993). In other words, category boundaries are relatively fuzzy, meaning that peripheral exemplars of a given category lying at the boundary are considered less prototypical than those at the core. Consequently, firms considered peripheral to "mainstream" competitor categories are likely to be ignored by current market leaders. This tendency can create a form of collective blind spot on the part of established players that can be exploited readily by new entrants with different approaches (cf. Abrahamson \& Fombrun, 1994; Zajac \& Bazerman, 1991). Anecdotally, for example, the U.K. retailer Marks and Spencer has been able to exploit its position as a peripheral exemplar to amass considerable market share in the grocery sector.

\section{The Social Construction of Competitor Definition}

Drawing on the insights of Weick's (1979) concept of enactment and related social constructionist notions (Berger \& Luckmann, 1967), Porac and his colleagues maintain that over time individuals' beliefs about the identity of their competitors, suppliers, and customers become highly unified through mutual enactment processes, in which subjective interpretations of externally situated information are objectified via behavior:
Thus, for example, when a group of managers define their businesses as clothing stores or supermarkets, their understanding of the competitive environment is crystallized within a mental model, and their competitive focus is slanted towards organizations they perceive as members of the same competitive set. It is easy to see how such perceptions might eventually become objectified and institutionalized through such devices as trade associations, specialized publications, and a particularistic language for describing logical ecological conditions. . . . . . In this view, competitive groups are more than analytical and economic abstractions of researchers; they represent the social psychological reality for member organizations. If this subjectivist perspective is true, it will be impossible to classify and understand organizational forms, at least at the micro-niche level, without describing the mental models that motivate mutually adjustive competitive activities. (Porac \& Thomas, 1990, p. 236)

The work of Porac and his colleagues thus provides fundamental insights into some of the generative mechanisms underpinning the interorganizational macrocultures notion. In this view, industries, strategic groups, and markets are sociocognitive constructions, created through a shared interpretation of reality among collectives of organizations, which come to define the boundaries of the competitive arena and on what bases the battles for competitive success are to be fought. The mental models of competitive strategists from rival firms become highly similar, thereby creating group-level beliefs about the marketplace because of the tendency of organizations to imitate one another, both directly and indirectly, as illustrated graphically in Figure 16.2. Each competitor is involved in an individual enactment process in which the mental models of its strategists are reciprocally intertwined with its strategic choices and the material conditions of the marketplace. Other 
parties involved in the same transactional network, however, are also enacting their beliefs through activities within the marketplace. Although the interpretations of customers, suppliers, and competitors are all involved in structuring the transactional network, it is the enactment processes of the latter that are particularly important because they serve to link firm-level and group-level competitive activities through the creation of socially shared belief systems.

Empirical support for the above line of theorizing was gathered by Porac et al. (1989) in a study of the Scottish knitwear industry, a study which revealed an overwhelming tendency for managers from a number of rival firms to disregard as competitors firms located outside the immediate vicinity of Scotland. Notwithstanding the fact that Scottish knitwear producers at the time of the study accounted for a mere $3 \%$ of the total amount of knitted outerwear manufactured on a worldwide basis, only firms within the immediate locality and which produced a

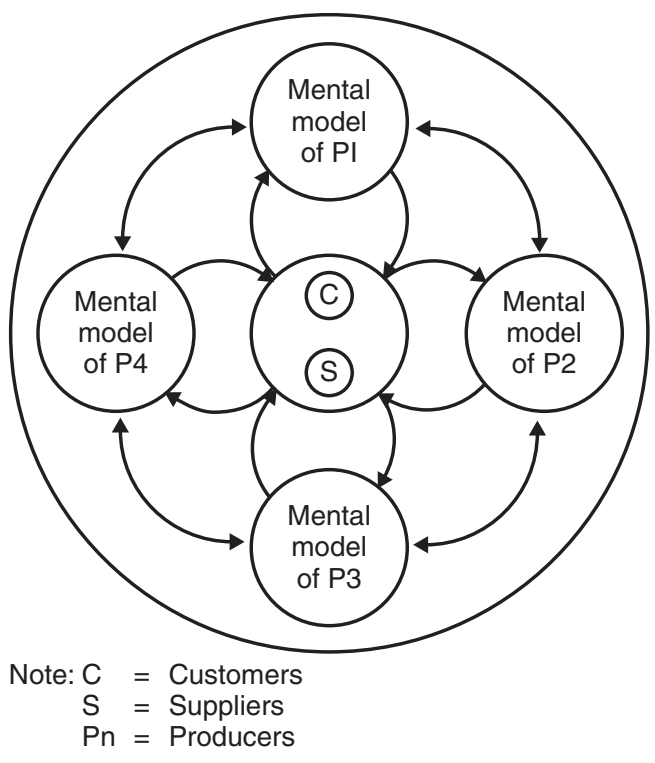

Figure 16.2 Mutual Enactment Processes Within an Industrial Sector

SOURCE: Porac, Thomas, and Baden-Fuller, 1989, p. 401. similar range of goods to one another, using similar technological processes of production and common channels of distribution, were regarded as serious competition. In a follow-up investigation, Porac et al (1995) identified a six-category model of organizational forms that seemed to capture actors' common perceptions of competition within this industry, with several attributes (principally size, technology, product style, and geographic location) forming the underlying basis for this commonly perceived structure.

\section{Elaborating the Mechanisms of Macrocultural Homogenization and Inertia}

The article by Abrahamson and Fombrun (1994) incorporated the fundamental insights of the above developments into the broader conception of macrocultures as a means of accounting for the collective failure of industries and interorganizational groupings in general to adapt to major environmental shifts, such as the entrance of radically different competitors and significant technological innovations, and break free from the shackles of the highly similar, but outdated, strategic postures adopted by member organizations:

Not only does the homogeneity of beliefs within an interorganizational macroculture inhibit adaptation by organizational members to changing environments, but it also influences how inventions arise and how quickly and completely they diffuse. In the last 20 years, relatively few technological innovations were developed within the culturally homogeneous U.S. auto industry, for instance, and the Big Three were visibly slow to imitate Japanese rivals.

In part, insularity and sluggishness result because homogeneity of beliefs within an interorganizational macroculture encourages member firms' managers to interpret environments in similar ways, to identify 
similar issues as strategic, and so to adopt similar competitive positions. (Abrahamson \& Fombrun, 1994, p. 729)

Building on the above foundations, there have been a number of developments, both theoretical and empirical, that cumulatively strengthen the basic argument that strategic actors embedded in value-added interorganizational networks will typically fall prey to the inertial vagaries of macrocultural homogeneity. The work of Lant and Baum (1995), for example, provides a series of complementary insights into the social construction of macrocultures through a consideration of isomorphism, the tendency observed by institutional theorists (e.g., DiMaggio \& Powell, 1983; Meyer \& Rowan, 1977) for organizations to develop shared beliefs, structures, networks of relations, and practices over time. Like Porac and his colleagues, Lant and Baum contend that managers engaged in interorganizational rivalry enact a structure of strategic groups, responding to and creating their competitive worlds in a manner consistent with their own cognitions. Illustrating their arguments by means of data they gathered in an empirical study of Manhattan hotel managers, Lant and Baum suggested that managers' conceptualizations of their strategic identities embodied in their shared categorization schemes give rise to the development of competitive groups within industries and the existence of isomorphic practices within these groups. According to Lant and Baum, two principal sources provide actors' with clues about their organization's strategic identity and hence its appropriate strategy: (1) cues arising from the monitoring of firms within the relevant competitive set (mimetic isomorphism) and (2) cues arising from a variety of normative sources such as the parent company (if the hotel is part of a conglomerate) and agents in the institutional environment who act as transmitters of information, including travel agents, higher education institutions, and industry consultants (normative isomorphism). Using a form of network analysis (Borgatti, Everett, \& Freeman, 1992) in conjunction with hierarchical cluster analysis, some 14 competitive groupings were identified from a total of 167 hotels. As predicted, managers within each discernible group of hotels tended to regard one another as relevant competitors. Also as predicted, a number of significant differences emerged between the competitive groups in relation to the mean size, price, and location (street and avenue) of the hotels, indicating that the aggregation of the competitive sets elicited from the individual managers reveals relatively homogeneous groups of hotels.

Peteraf and Shanley (1997) further explicated the role of identity processes in the formation and maintenance of cognitive strategic groups, borrowing concepts from social learning theory (Bandura, 1986; Wood \& Bandura, 1989) and social identification theory (Ashforth \& Mael, 1989; Tajfel \& Turner, 1986). They argued that managers reflect cumulatively on their experiences of interorganizational interactions, both direct and vicarious, to discern which firms are important for them to observe and emulate and which are of significance in competitive terms or for reasons of mutual concern. Over time, these observations and inferences about fellow firms are encoded in a series of routines that guide the future search behaviors of their organizations. According to Peteraf and Shanley, these routines steer the organization in such a way that it will tend to look to the same group of firms on repeated occasions, which in the long run leads to the development of a relatively stable cognitive entity. The accumulated experience gained through social learning enables organizations to reduce their transaction costs by promoting continued exchange only with those firms found to be reliable interaction partners, predictable in their behaviors and providing tolerable levels of risk. However, these processes of social learning 
are a necessary but insufficient condition for the emergence of strategic groups that have real and measurable effects, that is, groups that will ultimately influence the conduct and performance of their individual member organizations. In addition, social identification must occur; group members must not only perceive that a group exists (identification of the group), but also identify with the group. For Peteraf and Shanley, it is the identity strength of a strategic group that ultimately determines the extent to which group membership impacts on the conduct and performance of firms within a given industry.

\section{Rethinking the Dominant Assumptions}

The various theoretical and empirical advances summarized above seemingly lend further credence to Abrahamson and Fombrun's (1994) basic thesis. This chapter's purpose, however, is to revisit their analysis of the key determinants and consequences of interorganizational macrocultures. Although their propositions concerning the structural characteristics of interorganizational valueadded networks represented a useful starting point for theorizing the determinants and consequences of macrocultural homogeneity, their analysis does not take into account the effects of potentially important individual differences and intra-organizational processes and characteristics, including microcultural influences that likely mediate and moderate the nature and impact of macrocultures at the individual, group, organizational, and interorganizational levels of analysis. Accordingly, an ambitious program of work is required, entailing the generation of large-scale, multilevel, longitudinal datasets along similar lines to that envisaged originally by Abrahamson and Fombrun (1994) but which incorporates a range of additional variables to enable the modeling of complex cross-level interaction effects.
Even if strategic inertia becomes widespread within a given macrocultural grouping, this need not necessarily imply that terminal decline is inevitable. For example, key individuals might challenge the prevailing industry wisdom and competitive orthodoxy to such an extent that new competitive strategies emerge before too much damage is done. Levenhagen et al. (1993) developed a cognitive life cycle conception that offers some potentially useful insights into the question of how established macrocultures might evolve and change. Insights on this issue have also come from the situated learning perspective on strategic groups, advanced by Lant and Phelps (1999). Both perspectives provide support for the notion that the actions of key individuals (usually located on the periphery of value-added networks and often complete outsiders) can act as a catalyst for major change.

In the case of the life cycle conception, a primary task of key entrepreneurial agents is to destroy the legitimacy of extant categories of competitor definition, replacing them with a viable alternative. Such industry leadership demands that the frame-making entrepreneur is literally able to sell his or her vision to the wider community of actors within the competitive arena. Once a sufficiently critical mass of followers has developed, these newer competitive practices become objectified and institutionalized, until such time as further frame-breaking activities come to challenge afresh the prevailing orthodoxy.

As noted above, Peteraf and Shanley (1997) portrayed learning in interorganizational collectives as arising from a predominantly vicarious process involving the modeling or imitation of referent firms. This idea runs through many of the other developments outlined above. More recently, however, Lant and Phelps (1999) have challenged this rather basic view (see also Lant, 1999). They contend that, in reality, the emergence and evolution of such collectives is underpinned by a 
relatively complex, dynamic process. Ongoing interactions among the various players both central and peripheral to the group yield not only common and predictable patterns of behavior, but also help to preserve variations in the structures, strategies, and beliefs of member organizations within those groups. From this perspective, such variations are vital to the accomplishment of learning and change and enhance the longer-term survival capabilities of the wider population of organizations. Inspired by Wenger's (1998) work on situated learning and related conceptions (e.g., Araujo, 1998; Palinscar, 1998; Tsoukas, 1992), Lant and Phelps (1999) question the adequacy of the topographic view of organizations portrayed within the body of work outlined above and indeed much of the field of organization studies more generally. They take issue with two particular assumptions implicit in the topographic view-namely, that knowledge is localized in individual minds or other anthropomorphized entities such as organizations, and that organizations are relatively self-contained, bounded entities which learn through key individuals, such as top managers:

In contrast, we assume that learning, cognition, and knowledge are inherently situated in a broader social context consisting of actors, artifacts, language, time and space. According to a situated learning perspective, knowledge and its meaning are negotiated and constructed by actors who interact within a community with which they identify and who share the practices of the community ...

Situated learning encompasses meaning (learning as experience), practice (learning as doing), community (learning as becoming), and identity (learning as belonging). Such a view affords a much richer sense of the learning processes that occur within and among organizations than a focus on vicarious learning by top managers. (Lant \& Phelps, 1999, pp. 230-231)
In short, Lant and Phelps (1999) contend that the theory of learning and identification portrayed in extant social constructionist accounts of the emergence of strategic groups and identity in cognitive communities represents an undersituated perspective. As observed by Hodgkinson (2001a, p. 74), "Through its dynamic emphasis on the importance of both variation and consistency in cognition and action over varying time periods, the situated learning perspective draws attention to the importance of multi-level system interaction effects within and between firms and groups of firms." In marked contrast with the small sample, cross-sectional studies based upon single informant, multiorganization research designs that have dominated the literature pertaining to interorganizational macrocultures (e.g., Lant \& Baum, 1995; Porac \& Thomas, 1994; Porac et al., 1987, 1989; Reger \& Huff, 1993; Spencer, Peyrefitte, \& Churchman, 2003), this conception implies a strong need for studies in which the mental representations of multiple informants, situated at differing vantage points within and between organizations in the same industrial sector, are assessed repeatedly over time. As noted elsewhere (Hodgkinson, 1997a, 2001a, 2001b; Hodgkinson \& Sparrow, 2002), such studies would enable researchers to explore the extent to which, under what circumstances, and over what time scales and with what effect, actors' mental representations of competition converge, diverge, stabilize, and change. Unfortunately, however, with the notable exception of Lant (1999) and Lant and Phelps (1999), the vast majority of North American researchers who have investigated the social construction of interorganizational rivalry have implicitly or explicitly assumed away the significance of such variations in cognition, treating them as a source of unwanted error variance, and 
focused, instead, on the commonly reported perceptions and beliefs of top managers, typically the CEO, exemplified by the following remarks of Peteraf and Shanley (1997, pp. 167-168):

When a firm is led by a single top decision maker, as many small firms are, the cognitive processes of the CEO are arguably the same as those of the firm. This is because although the firm may be composed of many individuals, the CEO has full responsibility for scanning the environment and charting a course of action for the firm. Few would dispute that a cognitive analogy from individuals to firms is applicable in such a circumstance ... More often, however, a firm is managed by a top management team that exercises collective decision-making. In this case, the team may be characterized as a collective actor with cognitive capabilities if group-level processes . . . allow team members to reconcile their cognitive differences and make decisions in a relatively unified and consistent manner ... When the top management team is relatively homogeneous and when there is continuity of management, it is even more reasonable to view the firm as a collective cognitive actor.

This line of reasoning is predicated upon an implied level of microcultural consensus within the firm that is highly questionable (Floyd \& Wooldridge, 2000; Wooldridge \& Floyd, 1989). In fact, a considerable volume of theory and research emanating from the United Kingdom and wider continental Europe has identified a number of potentially significant sources of variation in mental representations of competitive space among individuals and subgroups within and between organizations inhabiting particular industries and markets. This body of work is entirely commensurate with Lant and Phelps's (1999) situated learning perspective, and in our view it forms the basis for advancing a much richer and complex counter-conception of the determinants and consequences of interorganizational macrocultures.

\section{THE CASE FOR MULTILEVEL RESEARCH: A EUROPEAN PERSPECTIVE}

Drawing on classic work at the intersections of strategy and organization theory (e.g., Bower, 1972; Hedberg \& Jonsson, 1977; Pettigrew, 1973, 1985; Pfeffer, 1981a, 1981b), Hodgkinson and Johnson (1994) argued that developing an adequate explanation of how organizations respond both individually and collectively to competitive pressures demands a more nuanced appreciation of the interplay of social, political, and cultural processes within and between organizations. A number of writers have demonstrated that there exist sets of relatively common assumptions related to different contexts. Strategists are likely to be influenced by, and interact with, all of these frames of reference (Huff, 1982). As depicted in Figure 16.3, these exist at the organizational level (Bartunek, 1984; Johnson, 1987, 1988; Laughlin, 1991; Pfeffer, 1981a; Prahalad \& Bettis, 1986; Sheldon, 1980) and, as acknowledged above, at the industry level (Grinyer \& Spender, 1979; Spender, 1989). However, the diversity of frames of reference upon which strategists draw goes still wider than the organizational or industry level. For example, there is evidence that national culture affects strategists' interpretations and responses to strategic issues (Schneider \& De Meyer, 1991) and their perceived control of the environment and strategic behavior (Hofstede, 1980; Kagono, Nonaka, Sakakibara, \& Okumura, 1985). There are also within-organization influences. At the level of functional groups (e.g., marketing, finance, production), for example, there are functionally specific belief systems that color group members' perceptions of issues 


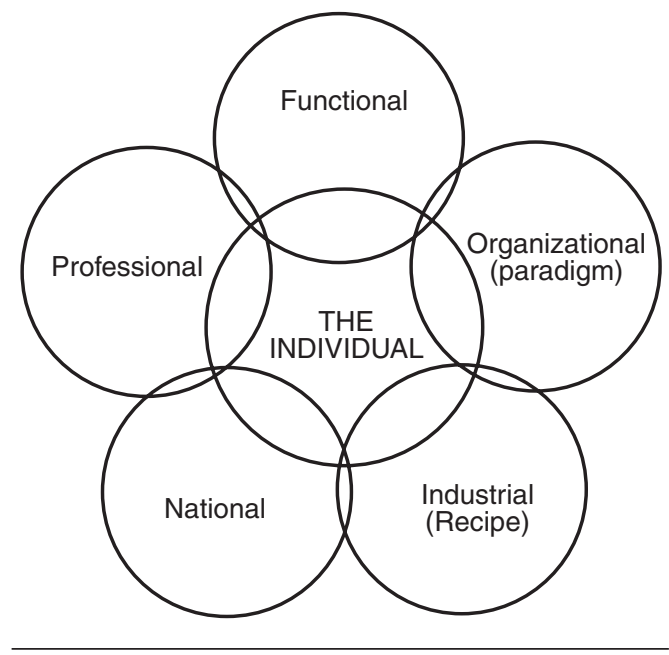

Figure 16.3 Frames of Reference of Strategists

SOURCE: Hodgkinson \& Johnson, 1994, p. 530.

(Dearborn \& Simon, 1958; Handy, 1985). Moreover, it has been argued that managers' views of the world are shaped at least in part by their career backgrounds (e.g., Gunz, 1989; Hambrick \& Mason, 1984; Whitley, 1987). Finally, there are various individuallevel frames of reference that may influence the way in which strategists perceive their competitive environments (Markus, 1977; Markus \& Nurius, 1986; Markus \& Wurf, 1987). Arguably, the primary reason for this diversity of cultural frames is that actors in different roles face different environmental contingencies, at least in terms of context, function, and level of responsibility (Lawrence \& Lorsch, 1967).

In sum, Hodgkinson and Johnson's (1994) analysis suggests that any actor or group of actors draws on a series of frames of reference to make sense of their world. There is a continual interplay between the individual, the context in which he or she operates, the frames of reference related to those contexts, and the political and social processes at work. Understanding the development and evolution of interorganizational macrocultures thus requires an appreciation of how these diverse frames of reference are reconciled within and between organizations. To the extent that this line of theorizing is correct, as a first step to validating it, it should be possible to detect meaningful patterns of difference and similarity in the structure and content of strategic actors' mental models of competitive space within the same industrial sector. In keeping with this line of reasoning, a number of predominantly U.K. and European studies have uncovered such patterns (see, e.g., Bowman \& Johnson, 1992; Calori, Johnson, \& Sarnin, 1992, 1994; de Chernatony, Daniels, \& Johnson, 1993; Daniels, Johnson, \& de Chernatony, 1994; Hodgkinson \& Johnson, 1994). Ironically, however, it was a North American study of the Chicago banking industry that first uncovered findings in keeping with the arguments of this chapter for a more nuanced, multilevel conception of the development and evolution of macrocultures:

A surprisingly low level of agreement as to the important strategic dimensions was found in this industry ... The results shown do not support the proposition that key strategic dimensions will be widely shared by strategists in an industry. . . It may be that subgroups of strategists in the industry share more commonality of dimensions than exhibited by the group as a whole. In particular, two subgroups are likely to share more commonality. First, members of the same BHC [bank holding company] might be expected to share more common dimensions because they interact more often with each other and are more likely directly to discuss competitors' strategies and key strategic dimensions in the industry. Second, strategists who share similar functional or product backgrounds are likely to share common dimensions because their training and experiences are similar and these may have shaped their cognitive constructive systems in similar ways. (Reger, 1990, pp. 77-79) 
Further evidence pointing to the need for a more nuanced understanding of intra- and interorganizational influences on strategic actors' representations of competitor definition was obtained in U.K. studies of the off-shore pumps (de Chernatony et al., 1993; Daniels et al, 1994) and grocery retail (Hodgkinson \& Johnson, 1994) industries. In the offshore pumps study, the revealed mental models of managers from differing functional backgrounds and organizations were compared directly. As in Reger's (1990) investigation of Chicago banks, the findings suggested considerable variation among the participants in terms of their views of the way in which the industry was structured. However, in keeping the various arguments outlined above concerning the potential importance of organizational and functional frames of reference, the results also indicated that managers within particular organizations shared more similar views than managers across organizations. Furthermore, managers within particular functional areas were found to be more similar in their views than managers across functional areas. The grocery retail sector study uncovered evidence of systematic variations in the structural complexity of actors' mental models of competition, which seemed to reflect key differences in the job demands of the informants.

Another study that lends credence to our call for a more nuanced appreciation of the determinants and consequences of interorganizational macrocultures is P. Johnson, Daniels, and Asch's (1998) study of the international automotive industry. On the basis of three separate sets of analysis, focusing on the competitors named by the participants, the number of constructs they employed and a content analysis of these constructs, P. Johnson and her colleagues concluded that there was little evidence of industry-, organizational-, or even group-level homogeneity in the knowledge structures that the managers held of their competitive environments. P. Johnson et al. (1998) attributed the variations between the pattern of findings observed in this study and those of the aforementioned offshore pumps and grocery retail sector studies to differences in analytic focus. The latter studies compared the content and structure of participants' cognitive maps, whereas P. Johnson and her colleagues confined their attention to an analysis of the content of their participants' cognitive maps. More generally, in a series of reviews, Hodgkinson (1997a, 2001a, 2001b, 2002, 2005) has identified a number of salient methodological differences across this group of studies as a whole, such that variations in the extent of individual, group, organizational and interorganizational homogeneity versus heterogeneity observed from one study to another are confounded (see also Hodgkinson \& Sparrow, 2002).

As argued by Hodgkinson (1997a), a common methodological limitation associated with virtually all of the studies reviewed in this section is that they have employed idiographic knowledge elicitation techniques, which necessitate extensive interactions between the researcher and participant. During the course of these interactions, there is ample opportunity for a range of factors associated with the dynamics of the interview (chiefly, the length of the interview and the behavior of the interviewer and interviewee) to influence the extent to which more or less elaborated cognitive maps are elicited. Consequently, it is difficult to ascertain the extent to which the observed differences in cognition are due to the characteristics of the industry under study, the characteristics of the individual participants and participating organizations, or the research methods employed to gather and analyze the data. These problems notwithstanding, sufficient evidence has accumulated overall to support the basic argument for a program of 
comparative work, with a view to identifying on a more thorough and systematic basis the relative influence of task, organizational, and extra-organizational influences on the development and evolution of interorganizational macrocultures.

\section{EXPLORING THE INTERPLAY OF MACROCULTURAL AND INTRA-ORGANIZATIONAL INFLUENCES ON COMPETITOR DEFINITION}

In the final analysis, both sets of theory and research outlined in this chapter must ultimately be reconciled if a truly comprehensive understanding of the dynamics of interorganizational macrocultures is to be developed (see also Sutcliffe \& Huber, 1998). Theories emphasizing the primacy of institutional forces such as mimetic adoption (e.g., Grinyer \& Spender, 1979; Lant \& Baum, 1995; Peteraf \& Shanley, 1997; Porac et al., 1989; Spender, 1989) suggest that managerial mental models within the same industry sector should move toward convergence at the level of the industry, strategic group, managerial function, and rank. Theories asserting the primacy of the competitive or task environment (e.g., Daniels et al., 1994; Hodgkinson \& Johnson, 1994), on the other hand, predict that a divergence of cognition should emerge between organizations, between management functions, and among managers of differing levels of seniority.

One study that attempted to reconcile the above explanations was conducted by Daniels, Johnson, and de Chernatony (2002). They sought to delineate the relative contributions of task and institutional influences as determinants of managerial representations of competitive industry structures in the U.K. financial services industry. Building upon both the North American and U.K.European streams of theory and research out- lined above, Daniels and his colleagues used the least squares dummy vectors approach to multiple regression (Cohen \& Cohen, 1983) to explore the relative contribution of managerial function, level of seniority, organizational membership, and the interaction effects of these variables on the overall levels of belief similarity versus dissimilarity across a diverse sample of participants. Interestingly, the overall pattern of findings suggested that neither task nor institutional explanations were inherently superior in accounting for participants' perceptions of this particular industry. Although there was some evidence that the institutional environment exerts significant influence (primarily through a convergence of mental models among middle managers across the industry), there was also evidence of significant task influences. In particular, a number of significant differences emerged across organizations, with greater differentiation among senior managers. In exploring the relative contributions of task and institutional forces, this study undoubtedly broke new ground by bringing into a unified framework the hitherto largely disparate streams of theory and research reviewed in this chapter. Unfortunately, however, as argued elsewhere (Hodgkinson, 2002), the methodological criticisms leveled against the studies reviewed in the previous section are no less applicable in the case of this particular study. In addition to the potentially biasing demand characteristics arising from the idiographic knowledge elicitation task employed by Daniels et al. (2002), the subsequent procedure adopted to assess the main dependent variable of overall levels of belief (dis)similarity may well also have biased the results obtained in favor of the substantive hypotheses under test.

It is somewhat curious that none of the studies reviewed thus far have adopted multiwave, multilevel longitudinal research designs, of the sort required ultimately to arbitrate between the competing theories regarding the homogenizing tendencies and inertial 
properties of interorganizational macrocultures (cf. Hodgkinson, 1997a). One notable exception in this respect is Hodgkinson's (1997b, 2005) prospective longitudinal study of the U.K. residential estate agency industry. This industry is ideal for competitively testing the validity of the competing claims of the various theories summarized above because it comprises a dense network of actors with strong, multilevel interdependencies that cross organizational boundaries. Using a weighted, three-way multidimensional scaling technique, Hodgkinson (1997b) found that a two-dimensional group space configuration (quality $\mathrm{x}$ market power) was sufficient both conceptually and statistically to meaningfully represent the perceptions of a sample of 206 participants drawn from 58 organizations (see Figure 16.4). Further detailed analyses (reported in Hodgkinson, 2005) found virtually no differences between this basic two-dimensional model and separate configurations derived for various organizational and functional subgroups. Accordingly, Hodgkinson (2005) concluded that his study provided a powerful demonstration of industry-wide competitive beliefs overwhelming more micro-level forces for intergroup belief divergence (cf. Calori et al., 1992; de Chernatony et al., 1993; Daniels et al, 1994; Hodgkinson \& Johnson, 1994; P. Johnson et al., 1998; Reger, 1990). Furthermore, a comparison of the configuration depicted in Figure 16.3 with one derived from follow-up data gathered some 12 to 18 months later revealed that participants' perceptions of the competitive environment had remained remarkably consistent, despite overwhelming objective evidence of a highly significant downturn in the domestic housing market from time 1 to time 2. Accordingly, Hodgkinson (1997b, 2005) concluded that his study also offered strong support for the cognitive inertia hypothesis. ${ }^{1}$

As noted by Hodgkinson (2002, 2005), with a little imagination on the part of future researchers, his three-way scaling procedure could easily be adapted to facilitate the rigorous investigation of actors' mental representations of a range of strategic issues and problems. The primary advantage of this approach lies in its inherent flexibility, being suitable for the detection of both convergence and divergence in actors' belief structures. Furthermore, as demonstrated, it enables large-scale, multilevel comparisons without the need to resort to cumbersome, post hoc coding procedures.

\section{SUMMARY, IMPLICATIONS, AND DIRECTIONS FOR FUTURE RESEARCH}

The overriding theme running throughout this review of the literature is that to understand the dynamics of interorganizational macrocultures, it is essential to consider forces at multiple levels of analysis-from the individual to the group, organizational, interorganizational, and (even inter-) industry levels. Yet attempts to model either theoretically or empirically how these multilevel forces interact are noticeable only by their absence. Hence, this section assesses the prospects for developing a more nuanced, cross-level understanding of the emergence, evolution, and transformation of macrocultures.

As indicated above, the evidence for the prevalence of homogenous macrocultures of competition is shaky at best. Although research in the North American tradition has emphasized industry belief convergence, another body of (mainly U.K. and European) research has demonstrated considerable divergence in competitor definition within and between organizations competing in the same industrial sectors. Hence, something of an impasse has been reached: How can there be at once both apparent agreement on the basis of competition between firms, 


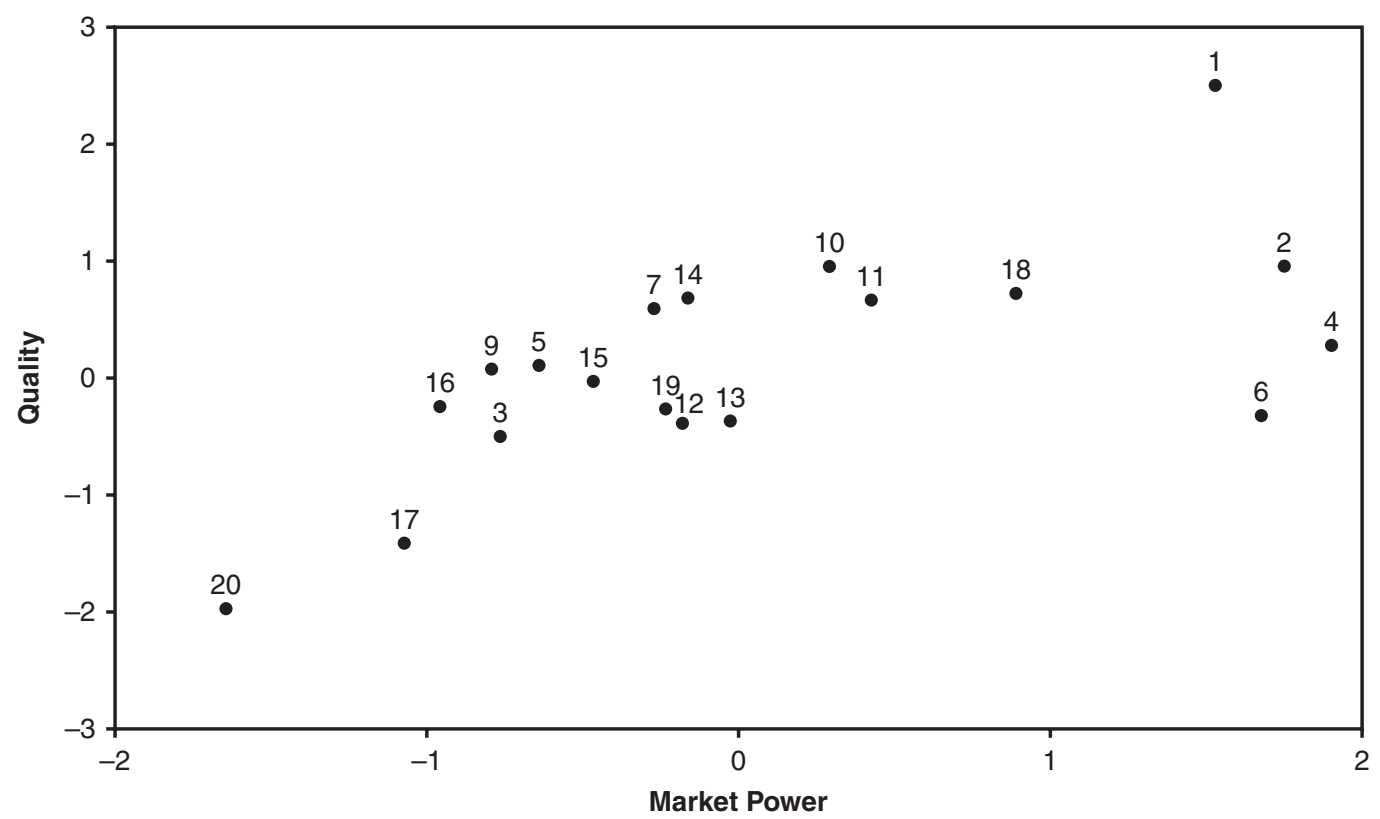

Key:

1. My Business

2. My Majaor Competitor

3. A Solicitor Agent

4. An Estate Agent Owned by a Building Society

5. A Traditional Estate Agent

6. An Estate Agent Owned by an Insurance Company

7. An Estate Agent Offering a Professional Service

8. An Estate Agent with a Poor Reputaion

9. An Estate Agent with Chartered Surveyor Status

10. An Estate Agent Specialising in Exclusive Property
11. An Estate Agent Specialising in Commercial and Industrial Propery

12. An Estate Agent Specialisng in Residential Property

13. A Secondary Competitor

14. An Estate Agent with a Good Reputation

15. A Diversified Estate Agent

16. An Independent Estate Agent

17. An Inferior Competitor

18. A Very Successful Estate Agent

19. A Moderately Succesful Estate Agent

20. An Unsuccessful Estate Agent

Figure 16.4 The Two-Dimensional Group Space Representation of the 20 Estate Agency Categories for the Full Sample of Respondents at T1 ( $N=206$; Stress = 0.212; RSQ $=0.846)$

SOURCE: Hodgkinson, 1997b, p. 935.

but also explicit disagreement between individuals within a given firm? Earlier, we suggested that one explanation for this paradox is largely methodological, with nomothetic methods tending to show convergence and idiographic methods tending to show divergence. The idea that divergence is a methodological artifact suggests that error variance or a mere measurement effect may be responsible for the mixed patterns of findings observed from one study to another. But this is only part of the story. Although key actors and organizations do behave in a way that seemingly demonstrates the type of convergence characterized by Abrahamson and Fombrun (1994), one does not need to scratch too far below the surface to observe clear and real signs of belief heterogeneity. Indeed, whenever researchers have looked for it, they have tended to find divergence. What, then, other than methodological factors, might explain this state of affairs? One possibility is that the discrepancy is due largely to differences between what individu- 
als and collectives say they do (i.e., inferring macrocultures from ostensive statements) and what they actually do in context (i.e. inferring macrocultures from performative action). However, the situated, interactional perspective outlined in this chapter favors a richer explanation, one that depicts competing forces for convergence versus divergence across levels of analysis.

Clearly, at each level of analysis there are sets of competing forces that variously drive individuals and collectives toward belief convergence and divergence. At the interorganizational level, while some firms strive for advantage by carving out a niche, others seek legitimacy from conformance. Deephouse's (1999) theory of strategic balance highlights the fundamental imperative for successful enterprises to strike the appropriate balance between fitting in with the established industry recipe and standing out from the crowd by differentiating themselves. At the individual level, while some decision makers seek security in adhering to the status quo views of the prevailing macroculture, others challenge that view in an attempt to gain the high ground within their organizations and beyond. Some key individuals are able to step outside a given macrocultural belief system to articulate an alternative conception of the competitive field. Indeed, these are the very individuals, often located on the periphery of the dense, centralized value-added networks that give rise to industry-wide homogeneity and inertia, who typically drive forward macrocultural changes by constructing and selling new visions of technologies and competitive practices (cf. Levenhagen et al., 1993; Lant \& Phelps, 1999). To transform the extant macroculture, these exceptional leaders must procure the necessary material resources and attract like-minded individuals, mobilizing their support for the novel ideas and innovative practices they are seeking to legitimate, thereby altering the dynamics of competition. However, operating against these change agents are the many individuals and groups who have so much invested in the extant macroculture that they will continue to enact the old worldview. Hence, the transformation of macrocultures is a nonlinear process, involving iterative cycles that eventually result in a new negotiated order.

The above analysis raises two important issues for the future advancement of theory and research. First, how exactly are particular individuals and collectives able to play the critical macrocultural frame-breaking role alluded to above? What are the traits of these entrepreneurial visionaries and what external forces enable and constrain their activities? Second, how should scholars best model cross-level interactions among the various forces that have been identified above as the potential drivers of macrocultural homogeneity versus heterogeneity and inertia versus change?

\section{Industry Leadership and the Individual-Level Drivers of Macrocultural Change}

At the individual level, an intriguing question deserving of sustained inquiry concerns the psychological characteristics of industry frame-breaking entrepreneurs. Equally pressing is the need to gain an understanding of the profile of those individuals who perpetuate cognitive inertia on an industrial scale. Although one set of personal characteristics is likely associated with conforming to prevailing macrocultural beliefs, such as the need for closure (Kruglanski \& Webster, 1996) and for affiliation (McGhee \& Teevan, 1967), another set likely facilitates framebreaking behavior and belief divergence, such as transformational leadership (Bass \& Riggio, 2006) and need for cognition (Cacioppo, Petty, Feinstein, \& Jarvis, 1996). Although it is known that industry leaders 
are frame breakers and frame makers, little is known about the psychological or behavioral competencies that underpin this crucial function. Without such understanding, it is difficult to build mechanisms for sustaining and developing these competencies in a way that reduces the likelihood of industry inertia and decline.

One particular line of argument suggests that a set of core beliefs concerning agency-determinism is important for understanding the role individuals play in the redefinition of interorganizational macrocultures (Hodgkinson, 2005). It is well known that differences in locus of control (Rotter, 1966) - the extent to which individuals generally perceive events to be primarily controlled by their own actions or caused by external forces beyond their grasp-governs the extent to which they also view themselves as shapers of, or hostages to, their firms' strategic activities (Carpenter \& Golden, 1997; Miller, Kets De Vries, \& Toulouse, 1982). Applying this same logic to macrocultures, locus of control beliefs, especially control expectancies pertaining to the specific domain of strategic management, that is, strategic locus of control (Hodgkinson, 1992, 1993), should influence the extent to which actors see themselves and their organizations as mere passengers, swept along by the ebb and flow of the prevailing industry dynamics, or as architects, shaping the future structure, conduct, and performance of the enterprise and its wider environment.

However, beyond the basic finding that companies whose CEOs are possessed with a strong sense of internality are more innovative in the marketplace, with a tendency to lead rather than to follow competitors (Miller et al., 1982), there has been little empirical study of this phenomenon. One exception is Hodgkinson's (2005) basic correlation analysis of the links between actors' strategic control expectancies, environmental scanning behaviors, mental models of competitor definition, and perceptions of the strategy, structure, and performance of their organizations or pertinent organizational subunits. Many intriguing questions remain unanswered: not least, the question of how the collective balance of strategic control expectancies within and across organizations might alter the evolutionary dynamics of interorganizational macrocultures more generally (cf. Hodgkinson, 1993). Is it the case that ceteris paribus firms with executive teams containing a majority of members high in internal locus of control are more likely to articulate new industry categories and develop innovations that challenge traditional market boundaries? What are the prospects when the composition is more mixed? More generally, what is the requisite mix of behavioral traits within strategy making teams that ultimately enable firms to strike the appropriate balance between fitting in and standing apart as articulated by Deephouse (1999) in his strategic balance theory? Beyond such basic demonstrations of effect lie questions regarding the most appropriate way to conceptualize individual differences in agentic versus deterministic control beliefs. Detecting the effects in question will depend in no small part on operationalizing constructs at the appropriate level of granularity. A noteworthy tension in this connection is the question of whether research should focus on narrow, intermediate, or broadband constructs (Hodgkinson \& Healey, 2008a). Broadband conceptions, exemplified by the five factor model of personality (e.g., Digman, 1990; Goldberg, 1993) and associated instruments for the assessment of the Big Five traits of extraversion, emotional stability, openness, agreeableness, and conscientiousness (e.g. Costa \& McCrae, 1992; Gill \& Hodgkinson, 2007) offer an elegant highlevel summary of variables relating to control expectancies but may miss the nuances that narrow-band conceptions (e.g., locus of control and self-efficacy) enjoy in predicting 
specific culture-shaping behaviors. In future, intermediate-level constructs such as core self-evaluation (combining self-esteem, selfefficacy, locus of control, and emotional stability) may represent one potential means of optimizing this trade-off (Hiller \& Hambrick, 2005).

A further aspect of understanding the micro-level origins of macrocultural transformation concerns the social, political, and interpersonal cognitive dynamics of this process. Clearly, no one individual stands a chance of transforming a macroculture on his or her own. Sensemaking researchers have made great strides in exploring the cognitive and sociopolitical processes through which actors break down existing frames, articulate new ones, and mobilize support for those new conceptions within firms (e.g. Fiol, 1994). A valuable extension to this line of work would be to examine the specific influence processes analogous to sense-breaking and sensegiving detected within organizations (e.g., Pratt, 2000; Maitlis, 2005) at the industry level. Precisely how do firms and groups of firms successfully challenge extant models of competition, use appropriate language and cultural devices to articulate new product categories, and persuade others of the value of novel industry practices?

\section{Modeling the Multilevel Determinants and Consequences of Macrocultures}

Perhaps the most fascinating aspect of macrocultures concerns the competing views on industries as top-down shapers of the mindsets of constituent organizations versus organizations as bottom-up shapers of industry logics. As noted above, the prevailing view is still one of industry assumptions shaping intra-organizational microcultures, and research from various perspectives has overwhelmingly sought to validate this assumption (see also Gordon, 1991). An alternative way to characterize this dynamic is to view it as a multidirectional, multilevel battle of wills, a contestation of agency versus structure fought between actors and institutions via a series of top-down and bottom-up influence processes. But progress in building such a nuanced understanding has been slow, largely because empirical analyses of the sophistication ultimately required for modeling the interplay among the various forms of individual, sociopolitical, and cultural influences identified throughout this chapter have been in short supply. Part of the reason for this shortfall is methodological. It is relatively easy to stand back and identify in a retrospective manner shared beliefs once an industry has reached a certain degree of convergence-the signs of homogeneity are everywhere. But it is more difficult to identify pockets of culture-breaking innovation in a prospective manner and then track the diffusion of the new logics of competition over time.

Although the literature reviewed in this chapter has centered primarily on cultures of competition, it is worth noting that there have been several attempts to broaden the analysis of mindsets pertaining to the external business environment, so as to encompass a range of additional issues and problems. Phillips's (1994) analysis of shared industry mindsets among organizations within the fine arts museums and Californian wine industries, for example, revealed that informants' shared beliefs within each industry were not restricted to competition per se; rather, they also shared common views regarding issues as varied as "the nature of truth," "the purpose of work," and "the nature of work relationships." Her overall analysis supports the basic arguments presented in this chapter concerning the idea that "a multiplicity of dynamic, shared mindsets exists within an organization's environment" (Phillips, 1994, p. 384). More recently, Tyler and Gnyawali (2009) examined actors' beliefs pertaining to 
the broader notion of customer orientation in addition to those pertaining to competitor activity, albeit within the confines of a single organization, a subsidiary of a major multinational food company. The idea at the heart of this chapter that multiple cultural mindsets coexist within and between industries raises fundamental new questions about their potential interrelationships. Phillips's (1994) study, for example, suggests that the broader social and ideological beliefs shared within a given industry influence the way that actors view competition. The fundamental belief held in both the wine and arts museums industries that the respective products and services in question constituted a superior means of enhancing the human condition led to a view of competition in each case that transcended industry-specific categories. More particularly, the core idea shared widely within the museums industry that their services provided enlightenment to the masses perpetuated the view that museums were competing with less worthy leisure activities (e.g., amusement arcades). Similarly, the idea that wine provides more sophisticated sensory satisfaction led to the view held widely within the wine industry that it is competing with the liquor and beer industries. Further research on how multiple industry mindsets interact in this manner will surely provide a broader understanding of the origins and dynamics of macrocultures beyond competition per se.

One obvious domain of activity that could be further incorporated within a broader conception of interorganizational macrocultures is the domain of security and risk. From a policy-making and practitioner perspective, as well as for the purposes of theory extension, it would be helpful to know to what extent and in what ways the insights generated from the macrocultural analysis of competitive dynamics shed light on the increasingly pressing problem of how organizations within and between industries construe and collectively respond to the threats of terrorism and organized serious crime. Emerging work in the domain of risks pertaining to the use of information technology in the workplace (e.g., Coles \& Hodgkinson, 2008), for instance, suggests that the homogenizing and inertial effects of interorganizational macrocultures are likely no less prevalent in this domain.

In more general terms, relatively little is known about the effects of industry network characteristics on the development of macrocultures. Abramson and Fombrun (1994) argued persuasively that network characteristics would affect divergence and convergence processes, but empirical study has been slow to emerge. Nobody has yet undertaken the comparative longitudinal studies required to demonstrate that differences in industry structure (e.g., in network density, regulatory activity, interfirm transactions) do, indeed, lead to strong versus weak macrocultures. Recent developments in social network analysis have put researchers in a better position to first characterize the morphology of discrete collectives of organizations and then to structurally locate particular actors within them, as a precursor to the comparative analysis of the structure and content of mental models of competition. In terms of the origins of macrocultural innovation, it would appear that the field can learn much from the activities of influential outliers-those network outsiders who, paradoxically, are often at the heart of industry innovation.

It should be apparent by now that methodological challenges are a major barrier to the kind of empirically driven, crosslevel understanding of macrocultures that has been alluded to in this chapter. Four specific empirical desiderata for future research have been identified: (1) the gathering of multiwave longitudinal data to enable trend analysis, (2) a widening of the net to capture both a greater sample of firms and firm subgroups within a given industry (e.g., at different points in the value chain) and 
a wider array of respondents (i.e., beyond the top team) within individual firms, (3) the simultaneous capture of exogenous independent variables at different levels of analysis as potential predictors of homogeneity versus heterogeneity, and (4) an assessment of dependent variables relating to strategic inertia and adaptation, both at the industry and firm levels. It is encouraging that researchers are beginning to make progress toward some of these goals. Ng, Westgren, and Sonka's (2009) recent study is exemplary in its use of relatively large numbers of respondents to demonstrate belief heterogeneity in perceptions of competition between actors located at different points in an industry's value chain. However, the gold standard envisaged in this chapter requires a considerably larger program of research, perhaps on the scale of the Global Leadership and Organizational Behavior Effectiveness (GLOBE) projectthe much-lauded, multiphase, cross-national study of the interrelationships between societal culture, organizational culture, and organizational leadership (House, Hanges, Javidan, Dorfman, \& Gupta, 2004). The adoption of multilevel modeling techniques (Klein \& Kozlowski, 2000) to examine the relative and interacting influence of variables at the different levels of analysis highlighted above would similarly be a significant step forward in understanding the nature and influence of macrocultures.

One potentially profitable way to circumvent some of the challenges associated with the fundamental requirement for large-scale datasets to resolve the various competing claims outlined above is to analyze simulated or secondary data. D. R. Johnson and Hoopes (2003) have recently demonstrated the value of mathematical modeling with simulated data. Their analysis suggests that the interaction between cognition and economic industry structure can account for the seemingly conflicting findings regarding the formation and evolution of macrocultural beliefs. When firms attend to only a small set of competitors, beliefs within a focal cluster of firms homogenize. Hence, when competitive pressure is localized and information search is costly, managers across an industry will tend to hold different beliefs about that industry. The field awaits cross-validation of these potentially important insights using real industry data. In the meantime, the analysis of documentary sources such as industry association reports and the annual reports of constituent firms (e.g., Kabanoff \& Brown, 2008; Nadkarni \& Barr, 2008; Osborne, Stubbart, \& Ramaprasad, 2001) provides a potentially valuable means of assessing the development and consequences of macrocultures over time, without having to resort to the gathering of primary data through numerous face-to-face interviews and potentially lengthy questionnaires. Indeed, this type of method seems particularly appropriate for capturing the artifacts of macrocultural cognition, as opposed to the idiosyncratic personal beliefs of individual actors (cf. Hodgkinson \& Sparrow, 2002).

\section{CONCLUDING REMARKS}

The chaos caused by the ongoing global banking crisis has heightened the need to refine understanding of the origins and dynamics of macrocultures. Recent events illustrate dramatically why a more nuanced, multilevel appreciation of cultural influences on the behavior of collectives of organizations is of crucial importance, not only for the advancement of scholarly theory and research, but also for managing the myriad of individual, group, organizational, and interorganizational processes that variously shape and reinforce the collective beliefs and behaviors of mass populations of actors and firms. Despite numerous interventions on the part of world leaders to mediate the ongoing crisis, the bonus culture, which ultimately underpins the reluctance on 
the part of banks and related financial services companies to release the loans demanded by businesses and consumers to stimulate the global economy, has continued apace. There have been very few discernible changes in the behavior of individual bank employees and their organizations. On the contrary, beliefs and practices have converged to a such an extent that the various institutions in this sector have fallen foul of an industry-level blind spot so powerful that those employed to lead and govern are incapable of comprehending, let alone responding to, the high levels of anger and sense of moral outrage on the part of ordinary citizens (cf. Stiglitz, 2010). Macrocultural inertia is preventing wholesale changes to the way in which executives and employees alike are compensated for their efforts.

When viewed through the lens of macrocultural theory and research, recent events raise several dilemmas for policy makers and industry leaders. What role might regulators play in alleviating and/or intensifying macrocultural inertia? Applying the logic of requisite variety (Ashby, 1958), a certain degree of intra-industry variation in perceptions of competition and competitive structure might help to alleviate the natural tendency toward inertia-inducing homogeneity. Industries, like organizations, must balance the need for cognitive convergence with the need for requisite cognitive variety. Although competitive and market forces might generally stimulate such a balance, recent events illustrate that sometimes that balance slips. Although many regulatory practices likely inculcate homogeneity in the understanding of industry norms and practices, the foregoing analysis suggests that there may be a place for regulatory intervention to stimulate variations in mental models of competition. Techniques such as scenario analysis might be valuable here, serving an analogous purpose at the industry level to that served at the intraorganizational level-that is, the stimulation of adaptive cognitive change among key individuals and groups (see Healey \& Hodgkinson, 2008; Hodgkinson \& Healey, 2008 b). Similarly, given that industry leaders play an important part in bolstering the responsiveness of industries, there may be adequate justification for even greater regulatory support for industry thought leadership. Understanding these critical roles is just one of a number of important undertakings for future research on the development and consequences of interorganizational macrocultures.

\section{NOTES}

1. For the sake of completeness, it should be noted that further analyses revealed marked variations at the individual level in the relative salience of these commonly perceived market power and quality dimensions. A comparison of the participant source weight ratios, a variable derived to capture individual differences in dimensional salience, revealed no significant differences across the time 1 and time 2 datasets, thus lending further support to the cognitive inertia hypothesis. Additional work reported in Hodgkinson (2005) beyond the scope of this chapter found meaningful correlations between these ratios and a number of pertinent attitudinal and behavioral variables including locus of control, environmental scanning, and the participants' perceptions of the strategy, structure, and performance of their organizations or pertinent organizational subunits. 


\section{REFERENCES}

Abrahamson, E., \& Fombrun, C. J. (1994). Macrocultures: Determinants and consequences. Academy of Management Review, 19, 728-755.

Araujo, L. (1998). Knowing and learning as networking. Management Learning, 29, 317-336.

Ashby, W. R. (1958). Requisite variety and its implications for the control of complex systems, Cybernetica, 1, 83-99.

Ashforth, B. E., \& Mael, F. (1989). Social identity theory and the organization. Academy of Management Review, 14, 20-39.

Bandura, A. (1986). Social foundations of thought and action: A social cognitive theory. Englewood Cliffs, NJ: Prentice Hall.

Bartunek, J. M. (1984). Changing interpretive schemes and organizational restructuring: The example of a religious order. Administrative Science Quarterly, 29, 355-372.

Bass, M. B., \& Riggio, E. G. (2006). Transformational leadership (2nd ed.). Mahwah, NJ: Lawrence Erlbaum.

Berger, P. L., \& Luckmann, T. (1967). The social construction of reality. Harmondsworth, UK: Penguin.

Borgatti, S. P., Everett, M. G., \& Freeman, L. C. (1992). UCINET IV Version 1.0. Columbia, SC: Analytic Technologies.

Bower, J. L. (1972). Managing the resource allocation process: A study of corporate planning and investment. Homewood, IL: Irwin.

Bowman, C., \& Johnson, G. (1992). Surfacing competitive strategies. European Management Journal, 10, 210-219.

Cacioppo, J. T., Petty, R. E., Feinstein, J. A., \& Jarvis, W. B. (1996). Dispositional differences in cognitive motivation: The life and times of individuals varying in need for cognition. Psychological Bulletin, 119, 197-253.

Calori, R., Johnson, G., \& Sarnin, P. (1992). French and British top managers' understanding of the structure and dynamics of their industries: A cognitive analysis and comparison. British Journal of Management, 3, 61-78.

Calori, R., Johnson, G., \& Sarnin, P. (1994). CEO's cognitive maps and the scope of the organization. Strategic Management Journal, 15, 437-457.

Carpenter, M. A., \& Golden, B. R. (1997). Perceived managerial discretion: A study of cause and effect. Strategic Management Journal, 18, 187-206.

Caves, R. E., \& Porter, M. E. (1977). Entry barriers to mobility barriers: Conjectural decisions and contrived deterrence to new competition. Quarterly Journal of Economics, 91, 241-261.

Cohen, J., \& Cohen, P. (1983). Applied multiple regression/correlation analysis for the behavioral sciences (2nd ed.). Hillsdale, NJ: Lawrence Erlbaum.

Coles, R., \& Hodgkinson, G. P. (2008). A psychometric study of information technology risks in the workplace. Risk Analysis, 28, 81-93.

Costa, P. T., \& McCrae R. R. (1992). The NEO PI-R professional manual. Odessa, FL: Psychological Assessment Resources.

Daniels, K., Johnson, G., \& de Chernatony, L. (1994). Differences in managerial cognitions of competition. British Journal of Management, 5, 21-29.

Daniels, K., Johnson, G., \& de Chernatony, L. (2002). Task and institutional influences on managers' mental models of competition. Organization Studies, 23, 31-62. 
de Chernatony, L., Daniels, K., \& Johnson, G. (1993). A cognitive perspective on managers' perceptions of competition. Journal of Marketing Management, 9, 373-381.

Dearborn, D. C., \& Simon, H. A. (1958). Selective perception: A Note on the departmental identifications of executives. Sociometry, 21, 140-144.

Deephouse, D. L. (1999). To be different, or to be the same? It's a question (and theory) of strategic balance. Strategic Management Journal, 20, 147-166.

Digman, J. M. (1990). Personality structure: Emergence of the five factor model. Annual Review of Psychology, 41, 417-440.

DiMaggio, P. J., \& Powell, W. W. (1983). The iron cage revisited: Institutional isomorphism and collective rationality in organizational fields. American Sociological Review, 48, 147-160.

Fiol, C. M. (1994). Consensus, diversity, and learning in organizations. Organization Science, 5, 403-420.

Floyd, S. W., \& Wooldridge, B. (2000). Building strategy from the middle: reconceptualizing strategy process. Thousand Oaks: Sage.

Gill, C. M., \& Hodgkinson, G. P. (2007) Development and validation of the fivefactor model questionnaire (FFMQ): An adjectival-based personality inventory for use in occupational settings, Personnel Psychology, 60, 731-766.

Goldberg, L. R. (1993). The structure of phenotypic personality traits. American Psychologist, 48, 26-33.

Gordon, G. G. (1991). Industry determinants of organizational culture. Academy of Management Review, 16, 396-415.

Grinyer, P., \& Spender, J.-C. (1979). Recipes, crises and adaptation in mature businesses. International Studies of Management and Organization, IX, 113-123.

Gripsrud, G., \& Gronhaug, K. (1985). Structure and strategy in grocery retailing: A sociometric approach. Journal of Industrial Economics, XXXIII, 339-359.

Gunz, H. (1989). Careers and corporate cultures: managerial mobility in large corporations. Oxford, UK: Basil Blackwell.

Hambrick, D. C., \& Mason, P. A. (1984). Upper echelons: The organization as a reflection of its top managers. Academy of Management Review, 9, 193-206.

Handy, C. B. (1985). Understanding organisations (3rd ed.). Harmondsworth, UK: Penguin.

Hedberg, B., \& Jonsson, S. (1977). Strategy making as a discontinuous process. International Studies of Management and Organization, 8, 88-109.

Healey, M. P., \& Hodgkinson, G. P. (2008). Troubling futures: Scenarios and scenario planning for organizational decision making. In G. P. Hodgkinson \& W. H. Starbuck (Eds.), Oxford handbook of organizational decision making (pp. 565-585). Oxford, UK: Oxford University Press.

Hiller, N. J., \& Hambrick, D. C. (2005). Conceptualizing executive hubris: The role of (hyper-) core self-evaluations in strategic decision-making. Strategic Management Journal, 26, 297-319.

Hodgkinson, G. P. (1992). Development and validation of the strategic locus of control scale. Strategic Management Journal, 13, 311-317.

Hodgkinson, G. P. (1993). Doubts about the conceptual and empirical status of context-free and firm-specific control expectancies: A reply. Strategic Management Journal, 14, 627-631.

Hodgkinson, G. P. (1997a). The cognitive analysis of competitive structures: A review and critique. Human Relations, 50, 625-654. 
Hodgkinson, G. P. (1997b). Cognitive inertia in a turbulent market: The case of UK residential estate agents. Journal of Management Studies, 34, 921-945.

Hodgkinson, G. P. (2001a). The psychology of strategic management: Diversity and cognition revisited. In C. L. Cooper \& I. Robertson (Eds.), International review of industrial and organizational psychology (pp. 76-119). Chichester, UK: Wiley.

Hodgkinson, G. P. (2001b). Cognitive processes in strategic management: Some emerging trends and future directions. In N. Anderson, D. S. Ones, H. K. Sinangil, \& C. Viswesvaran (Eds.), Handbook of industrial, work and organizational psychology (Vol. 2, pp. 416-440). London: Sage.

Hodgkinson, G. P. (2002). Comparing managers' mental models of competition: Why self-report measures of belief similarity won't do. Organization Studies, 23, 63-72.

Hodgkinson, G. P. (2005). Images of competitive space. Basingstoke, UK: Palgrave Macmillan.

Hodgkinson, G. P., \& Healey, M. P. (2008a). Cognition in organizations. Annual Review of Psychology, 59, 387-417.

Hodgkinson, G. P., \& Healey, M. P. (2008b). Toward a (pragmatic) science of strategic intervention: Design propositions for scenario planning. Organization Studies, 29, 435-457.

Hodgkinson, G. P., \& Johnson, G. (1994). Exploring the mental models of competitive strategists-the case for a processual approach. Journal of Management Studies, 31, 525-551.

Hodgkinson, G. P., \& Sparrow, P. R. (2002). The competent organization: A psychological analysis of the strategic management process. Buckingham, UK: Open University Press.

Hofstede, G. W. (1980). Culture's consequences: International differences in work related values. London: Sage.

House, R. J., Hanges, P. J., Javidan, M., Dorfman, P. W., \& Gupta, V. (Eds.). (2004). Leadership culture and organizations: The GLOBE study of 62 societies. Thousand Oaks, CA: Sage.

Huff, A. S. (1982). Industry influences on strategy formulation. Strategic Management Journal, 3, 119-130.

Johnson, D. R., \& Hoopes, D. G. (2003). Managerial cognition, sunk costs, and the evolution of industry structure. Strategic Management Journal, 24, 1057-1068.

Johnson, G. (1987). Strategic change and the management process. Oxford, UK: Blackwell Press.

Johnson, G. (1988). Rethinking incrementalism. Strategic Management Journal, 9, 75-91.

Johnson, P., Daniels, K., \& Asch, R. (1998). Mental models of competition. In C. Eden, \& J.-C. Spender (Eds.), Managerial and organizational cognition: Theory, methods and research (pp. 130-146). London: Sage.

Kabanoff, B., \& Brown, S. (2008). Knowledge structures of prospectors, analyzers, and defenders: Content, structure, stability, and performance. Strategic Management Journal, 29, 149-171.

Kagono, T., Nonaka, I., Sakakibara, K., \& Okumura, A. (1985). Strategic versus evolutionary management: A US-Japan comparison of strategy and organisation. Amsterdam: Elsevier Science.

Klein, K. J., \& Kozlowski, S. W. J. (Eds.). (2000). Multilevel theory, research, and methods in organizations. San Francisco: Jossey-Bass. 
Kruglanski, A. W., \& Webster, D. M. (1996). Motivated closing of the mind: "Seizing" and "Freezing." Psychological Review, 103, 263-283.

Lant, T. K. (1999). A situated learning perspective on the emergence of knowledge and identity in cognitive communities. In J. Porac \& R. Garud (Eds.), Advances in managerial cognition and organizational information processing (Vol. 6, pp. 171-194). Greenwich, CT: JAI Press.

Lant, T. K., \& Baum, J. C. (1995). Cognitive sources of socially constructed competitive groups: Examples from the Manhattan hotel industry. In W. R. Scott \& S. Christensen (Eds.), The institutional construction of organizations: International and longitudinal studies (pp. 15-38). Thousand Oaks, CA: Sage.

Lant, T. K., \& Phelps, C. (1999). Strategic groups: A situated learning perspective. Advances in Strategic Management (Vol. 16, pp. 221-247). Greenwich, CT: JAI Press.

Laughlin, R. C. (1991). Environmental disturbances and organizational transitions and transformations: Some alternative models. Organization Studies, 12, 209-232.

Lawrence, P. R., \& Lorsch, J. W. (1967). Organization and environment: Managing differentiation and integration. Boston: Harvard University Press.

Levenhagen, M., Porac, J. F., \& Thomas, H. (1993). Emergent industry leadership and the selling of technological visions: A social constructionist view. In J. Hendry \& G. Johnson (Eds.), Strategic thinking: Leadership and the management of change (pp. 69-87). Chichester, UK: Wiley.

Maitlis, S. (2005). The social processes of organizational sensemaking. Academy of Management Journal, 48, 21-49.

Markus, H. (1977). Self schemata and processing information about the self. Journal of Personality and Social Psychology, 35, 63-78.

Markus, H., \& Nurius, P. (1986). Possible selves. American Psychologist, 41, 954-969.

Markus, H., \& Wurf, E. (1987). The dynamic self-concept: A social psychological perspective. Annual Review of Psychology, 38, 299-337.

McGhee, P. E., \& Teevan, R. C. (1967). Conformity behavior and need for affiliation. Journal of Social Psychology, 72, 117-121.

Meyer, J. W., \& Rowan, B. (1977). Institutionalized organizations: Formal structure as myth and ceremony. American Journal of Sociology, 83, 340-363.

Miller, D., Kets De Vries, M. F. R., \& Toulouse, J. M. (1982). Top executive locus of control and its relationship to strategy-making, structure, and environment. Academy of Management Journal, 25, 237-253.

Nadkarni, S., \& Barr, P. S. (2008). Environmental Context, Managerial Cognition, and Strategic Action: An Integrated View. Strategic Management Journal, 29, 1395-1427.

Ng, D., Westgren, R., \& Sonka, S. (2009). Competitive blind spots in an institutional field. Strategic Management Journal, 30, 349-369.

Osborne, J. D., Stubbart, C. I., \& Ramaprasad, A. (2001). Strategic groups and competitive enactment: A study of dynamic relationships between mental models and performance. Strategic Management Journal, 22, 435-454.

Oster, S. M. (1990). Modern competitive analysis. New York: Oxford University Press.

Palinscar, A. S. (1998). Social constructivist perspectives on learning and teaching. Annual Review of Psychology, 49, 345-375. 
Peteraf, M., \& Shanley, M. (1997). Getting to know you: A theory of strategic group identity. Strategic Management Journal, 18, 165-186.

Pettigrew, A. M. (1973). Politics of organizational decision-making. London: Tavistock Institute.

Pettigrew, A. M. (1985). The awakening giant: Continuity and change in ICI. Oxford, UK: Blackwell Press.

Pfeffer, J. (1981a). Management as symbolic action: The creation and maintenance of organizational paradigms. In L. L. Cummings \& B. M. Staw (Eds.), Research in organizational behavior (Vol. 3, pp. 1-52). Greenwich, CT: JAI Press.

Pfeffer, J. (1981b). Power in organizations. Cambridge, MA: Ballinger.

Phillips, M. E. (1994). Industry mindsets: Exploring the cultures of two macroorganizational settings. Organization Science, 5, 384-402.

Porac, J. F., \& Rosa, J. A. (1996). Rivalry, industry models, and the cognitive embeddedness of the comparable firm. Advances in Strategic Management, 13, 363-388.

Porac, J. F., \& Thomas, H. (1990). Taxonomic mental models in competitor definition. Academy of Management Review, 15, 224-240.

Porac, J. F., \& Thomas, H. (1994). Cognitive categorization and subjective rivalry among retailers in a small city. Journal of Applied Psychology, 79, 54-66.

Porac, J. F., Thomas, H ., \& Baden-Fuller, C. (1989). Competitive groups as cognitive communities: The case of Scottish knitwear manufacturers. Journal of Management Studies, 26, 397-416.

Porac, J. F., Thomas, H., \& Emme, B. (1987). Knowing the competition: The mental models of retailing strategists. In G. Johnson (Ed.), Business strategy and retailing: (pp. 59-79). Chichester, UK: Wiley.

Porac, J. F., Thomas, H., Wilson, F., Paton, D., \& Kanfer, A. (1995). Rivalry and the industry model of Scottish knitwear producers. Administrative Science Quarterly, 40, 203-227.

Porter, M. E. (1980). Competitive strategy: Techniques for analyzing industries and competitors. New York: Free Press.

Prahalad, C. K., \& Bettis, R. A. (1986). The dominant logic: A new linkage between diversity and performance. Strategic Management Journal, 7, 485-501.

Pratt, M. G. (2000). The good, the bad, and the ambivalent: Managing identification among Amway distributors. Administrative Science Quarterly, 45, 456-493.

Reger, R. K. (1990). Managerial thought structures and competitive positioning. In A. S. Huff (Ed.), Mapping strategic thought (pp. 71-88). Chichester, UK: Wiley.

Reger, R. K., \& Huff, A. S. (1993). Strategic groups-a cognitive perspective. Strategic Management Journal, 14, 103-123.

Rosch, E. (1975). Cognitive reference points. Cognitive Psychology, 7, 532-547.

Rosch, E., Mervis, C., Gray, W., Johnson, D., \& Boyes-Braem, P. (1976). Basic objects in natural categories. Cognitive Psychology, 7, 573-605.

Rotter, J. B. (1966). Generalized expectancies for internal versus external control of reinforcement. Psychological Monographs: General and Applied, Whole no. $80(1), 609$.

Schneider, S. C., \& De Meyer, A. (1991). Interpreting and responding to strategic issues: The impact of national culture. Strategic Management Journal, 12, 307-320.

Sheldon, A. (1980). Organizational paradigms: A theory of organizational change. Organizational Dynamics, 8, 61-80. 
Spencer, B., Peyrefitte, J., \& Churchman, R. (2003). Consensus and divergence in perceptions of cognitive strategic groups: Evidence from the health care industry. Strategic Organization, 1, 203-230.

Spender, J.-C. (1989). Industry recipes: The nature and sources of managerial judgement. Oxford, UK: Blackwell Press.

Stiglitz, J. (2010). Freefall: Free markets and the sinking of the global economy. Harmondsworth, UK: Penguin.

Sutcliffe, K. M., \& Huber, G. P. (1998). Firm and industry as determinants of executive perceptions of the environment. Strategic Management Journal, 19, 793-807.

Tajfel, H., \& Turner, J. C. (1986). The social identity theory of intergroup behavior. In S. Worchel \& W. G. Austin (Eds.), Psychology of intergroup relations (2nd ed., pp. 7-24). Chicago: Nelson-Hall.

Tsoukas, H. (1992). Ways of seeing: Topographic and network representations in organization theory. Systems Practice, 5, 441-456.

Tyler, B. B., \& Gnyawali, D. R. (2009). Managerial collective cognitions: An examination of similarities and differences of cultural orientations. Journal of Management Studies, 46, 93-126.

Walton, E. J. (1986). Managers' prototypes of financial terms. Journal of Management Studies, 23, 679-698.

Weick, K. E. (1979). The social psychology of organizing (2nd ed.). New York: McGraw-Hill.

Wenger, E. (1998). Communities of practice. New York: Cambridge University Press.

Whitley, R. (1987). Taking firms seriously as economic actors: Towards a sociology of firm behavior. Organization Studies, 8, 125-147.

Wood, R. E., \& Bandura, A. (1989). Social cognitive theory of organizational management. Academy of Management Review, 14, 361-384.

Wooldridge, B., \& Floyd, S. W. (1989). Strategic process effects on consensus. Strategic Management Journal, 10, 295-302.

Zajac, E. J., \& Bazerman, M. H. (1991). Blind spots in industry and competitor analysis: Implications of interfirm (mis)perceptions for strategic decisions. Academy of Management Review, 16, 37-56. 